\title{
BUILDING INCLUSIVITY \\ INTO ASTROPHYSICS
}

\author{
MANY STEM FIELDS CONTINUE TO SUFFER FROM A LACK OF DIVERSITY - PEOPLE \\ FROM MINORITY BACKGROUNDS MISS OUT ON REWARDING CAREERS AND \\ SCIENCE MISSES OUT ON EXCEPTIONAL TALENT. DR RODOLFO MONTEZ JR. AND \\ CHRISTINE CROWLEY, OF THE SMITHSONIAN ASTROPHYSICAL OBSERVATORY IN \\ THE US, ARE ADDRESSING THIS ISSUE THROUGH AN INNOVATIVE INTERNSHIP \\ PROGRAMME THAT GIVES STUDENTS A REAL-LIFE TASTE OF A CAREER IN RESEARCH
}

Dr Rodolfo Montez Jr. is an astrophysicist at the Center for Astrophysics' Smithsonian Astrophysical Observatory (SAO), in Cambridge, Massachusetts. He and Christine Crowley, the SAO's Fellowship Program Director, run the SAO Latino Initiative Program (SAO LIP), an inspiring summer internship scheme that encourages local undergraduates from under-represented backgrounds to pursue careers in STEM.

\section{THE PROGRAMME'S ORIGINS}

"I vividly remember being one of only a handful of budding Latino astronomers at national meetings in the early 2000 s," says Rodolfo. "I found it very disconcerting. These days, it is more common to see young astronomers from all backgrounds, but we are still below expected representation." This issue of inclusivity is apparent across much of STEM, but especially within the 'hard sciences'. "Talented undergraduates from local communities are largely not choosing physics or astronomy," says Christine. "This is particularly true among promising STEM majors in the Latino and AfricanAmerican communities."
Christine and Rodolfo are addressing the false perception that there are few career opportunities within physics and astronomy for members of these communities. "The best research programmes are always the most diverse programmes," says Christine. "We found that students in the Urban Louis Stokes Alliance for Minority Participation in STEM enriched our programmes by providing original research and unique perspectives, and participants helped support their peers too. This inspired me to begin the Latino Initiative Program, aimed specifically at local minority undergraduate students."

Rodolfo agrees, motivated by his own personal experience. "As an underrepresented minority in STEM, I have always been interested in efforts to increase representation," says Rodolfo. "Since I was a graduate student, I have participated in and designed programmes that aim to improve representation in STEM, including mentor and research training and network building. When I arrived at the Smithsonian Astrophysical Observatory and learned about the LIP from Christine, I knew I had to get involved."

\section{THE SAO LATINO INITIATIVE PROGRAM}

The SAO LIP involves a summer internship that immerses students within important research, supported by an extensive mentor system. "A key element of the programme is that students are incorporated into significant research projects within astronomy and astrophysics," says Christine. "Most students are amazed at the level of responsibility they are given." She and Rodolfo believe that this first-hand experience of scientific research is the most effective strategy for inspiring their future career paths.

The SAO LIP is also flexible in the academic backgrounds it considers taking on, not limiting itself to applicants from 'hard science' backgrounds alone. "We take on students from many academic fields, so there are steep learning curves involved regarding learning the languages of astronomy and computer programming," 



\section{HOW DID RODOLFO BECOME AN ASTROPHYSICIST?}

As a child, I was interested in natural science and tinkering with my toys. I liked amphibians and reptiles. There was a time I would remove geckos from neighbours' houses for the low rate of 50 cents a gecko!

I was drawn to science early on, but I was turned towards accounting by my high school guidance counsellor. I was well into my accounting programme when I took an astronomy course to fulfil my science requirements. It was all I could talk about, so my friends told me to do that instead!
Creativity has played a big role in my success. I find it most rewarding when I make a new discovery by approaching the data with an innovative analysis - a creative perspective brings evidence to the surface and opens a new window into the universe.

My dream astrophysics project would be a next generation space telescope like the proposed Lynx observatory. This $\mathrm{X}$-ray telescope would be a successor to the telescope I currently help operate,
Chandra. The sensitivity of this telescope will throw the doors open to so many new discoveries.

I like to crochet, draw and cook. Crocheting gives me something to do while I mull over a problem, drawing gets me $50 \%$ of the way there but work is still on the periphery, while cooking takes me to a different head space entirely. I have also done fencing, ballroom dancing and graphic design!

\section{○ MEET THREE SAO LIP ALUMNI}

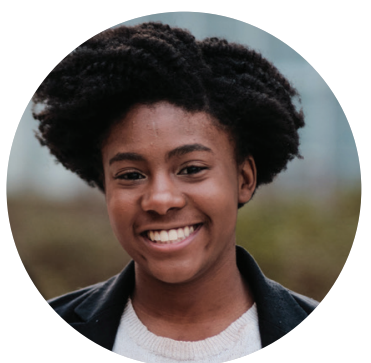

NAME: Arielle Joasil

\section{MAJOR: Electrical Engineering}

\section{CURRENT ROLE: Graduate}

Research Assistant in the CACT

(Center for Advanced Computation and Telecommunications); Master's student in Electrical Engineering at UMass Lowell
I was excited by what the LIP had to offer, and found that my electrical engineering skills were also applicable to problems in astrophysics. I also wanted to learn more about the researcher lifestyle.

For my first summer at the $\mathrm{SAO}, \mathrm{I}$ investigated how interactions between planets can remove moons from their host planet's orbit. My advisor and I found that it is likely that many white dwarfs (small stars) in the Milky Way are polluted by these 'lost' moons.

During my second summer, I worked on research and served as a peer mentor to other students, acting as a point of liaison for them, their advisors, and the programme coordinator. I also coordinated weekly computer programming sessions.

The programme was challenging intellectually, and I had to use my skills to build a foundation of understanding in unfamiliar territory. I found it exciting to expand my knowledge and solve a variety of problems.
A particular highlight was working with my advisor, Dr Matthew J. Payne; his support showed me how to do great work as a researcher, which really sparked my fascination.

Despite being a shy person, I found that stepping outside my comfort zone during the LIP and talking with different people helped me develop. This expanded further when I realised that I really enjoy mentoring others.

I would like to pursue a $\mathrm{PhD}$ in electrical engineering and complete work related to data science, machine learning, or signal processing. Ultimately, I hope to become a professor, which would allow me to conduct interesting research and mentor students.

Taking a chance and stepping outside your comfort zone can be very powerful. Your dreams may scare you, but you can achieve them - have faith in yourself! 


\section{PATHWAY FROM SCHOOL TO ASTROPHYSICS}

Rodolfo says that an understanding of maths and physics is essential for astrophysics, and that computer programming can be very useful. He recommends rounding out one's education with creative pursuits as well, either within school or as extra-curricular activities.

Christine says that in addition to a robust scientific foundation, a scientist also needs strong creative skills for writing about and publicising their research. She recommends taking courses such as English and public speaking to develop these skills.

\section{TOP TIPS FOR STUDENTS}

\section{RODOLFO'S TOP TIP:}

- The world is changing rapidly and we no longer need to compromise our identities - be yourself and celebrate who you are.

\section{CHRISTINE'S TOP TIPS:}

- Remember, there are many ways to have a career in science without getting a

$\mathrm{Ph} . \mathrm{D}$. Tutors and mentors can offer you invaluable advice to set you on the right path for you.

- Experiment with different career paths through internships.

- Learn to persist - obstacles are a natural part of your pursuit.

- If you can, spend a year abroad as a student or an employee.

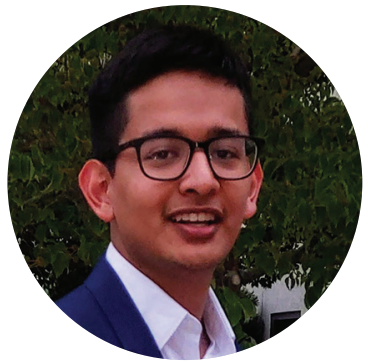

NAME: Fernando Mazzoni

\section{MAJOR: Physics}

CURRENT ROLE: M.S. Physics at University of Massachusetts Lowell

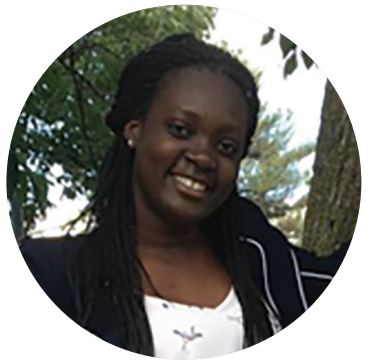

NAME: Shanelle Samuels

\section{MAJOR: Chemical Engineering}

\section{CURRENT ROLE: Process}

Development Associate at The Broad Institute of MIT and Harvard.
I applied to the programme because I wanted to carry out research and get to know more students and scientists from similar backgrounds to myself.

My research focused on understanding X-ray emissions from dwarf carbon stars (stars with more carbon than oxygen in their atmosphere). Unexpectedly, we found that these stars emit consistent $\mathrm{X}$-rays, meaning they had probably had mass transferred from another star in their lifetime.

My internship also involved meeting with my peers in workshops and attending plenary talks and seminars. At the end of the internship, we gave poster presentations of our research - I was very nervous beforehand, but it felt great discussing the research and left me feeling accomplished and successful.

The internship was my first time learning about astrophysics, undertaking real research, and using the computer programming language, Python. I lacked confidence at first, but the

This internship immediately caught my eye as I wanted to get some experience within the scientific community.

My research focused on assembling findings from experimental and theoretical studies that help detect molecules found within distant planets' atmospheres. This will help researchers to identify the types of planets their instruments pick up.

We had a weekly computer programming class where we learned to use Python. It was my first time learning to program in such depth and it was very worthwhile.

I received a lot of support from fellow scientists and students, especially the post-doctoral researchers who helped me feel welcome. I was programme made a great effort in making sure I was comfortable, and I quickly caught up on the necessary concepts.

I met my peer mentor regularly and my advisor weekly. They were both friendly, helpful and understanding.

Now, I can perform research-level analysis using Python, which is an invaluable skill. I have a much greater understanding of how professional research is done, and a firm grasp of the skills I need to become a STEM researcher.

Looking to the future, I hope to better understand the world around me and help others do the same. A lot of the skills I obtained from the programme can be helpful across a wider range of fields, and I hope to use them to support my community.

Things may seem overwhelming at times, but breathe, relax, and try your best. I recommend going for any opportunity that interests you - it never hurts to apply.

able to go to them for help at a moment's notice whenever things became difficult.

I learned a lot about how to work as part of a team to accomplish a goal. Computer programming has also come in useful with transitioning to other coding languages in subsequent classes. I am very proud of how far I came, especially within computer programming.

I hope to become a process engineer, utilising the skills I learned at this internship. Ultimately, I aspire to be a part of the Harvard Smithsonian as a fellow academic.

Soak up everything you can from the experience, and make sure to enjoy it as much as possible. 